\title{
EDITORIAL COMMENTS
}

\section{The Challenge for Rio: Reaching Everywhere on Earth by Means of Global Television}

$\mathrm{T}_{\mathrm{T}}^{\mathrm{h}}$ he great value of this Study Group* was to bring together as co-chairmen two people from the opposite ends of the spectrum of the environmental movement: Professor Polunin, distinguished academic, and editor for nearly twenty years of a leading environmental periodical that is rightly held in high regard throughout the world, and myself, a television producer of environmental programmes whose day-to-day task is to persuade television moguls that they should finance and transmit environmental documentaries instead of high-audience-rating quizzes and 'soap' operas.

My principal motive for accepting the invitation to participate, was to outline what I firmly believe to be the crucial role of the electronic media in influencing the global environmental agenda. And, of course, I was thinking particularly of the United Nations Conference on Environment and Development (UNCED), the event bringing together representatives from 178 countries and the greatest-ever number of heads of State and Government.

There seemed no doubt about UNCED - the so-called 'Earth Summit' - being the most-reported UN conference of all time, but such response of the world's television stations did not happen by accident. The One World project that was pegged to UNCED had begun two years earlier and been masterminded by a coregroup of the industrialized world's public service broadcasters led by the BBC and the German ARD networks and my own organization the International Television Trust for the Environment (TVE).

The question is, 'what now?'. What will happen when the TV crews leave Rio? How can we ensure that, in the years after UNCED, the world's TV screens continue to keep crucial environment and development issues in the public eye? Specifically, in a medium dominated by the hardware manufacturers and programme-makers of the industrialized world, how can we be sure that the voice of the South will be heard, and the Southern perspective on the global environmental crisis be screened? From TVE's standpoint, this was the challenge for Rio and the chosen subject of my brief address.

\section{UNCED and Public Awareness}

Out of 800 pages, the Agenda 21 document prepared for the Earth Summit devotes just two to the question of public awareness. Elsewhere in the document there are welcome, but scattered, references to the need to mount education and information programmes on some sectoral issues. Many of the recommendations are sensible, and we can be grateful that governments seem to be attaching some importance to the role of communications in promoting sustainable development.

But however positive a gloss one tries to put on the recommendations, it is difficult to come to any conclusion other than that communications will have only a low priority in Rio. This is curious when one considers that, had it not been for public pressure on governments, there probably would be no Earth Summit in the first place.

\section{Needed Free Flow of Communications}

It is now widely accepted that the supply of responsible public information is vital to sound environmental decision-making. As Dr Mostafa K. Tolba, UNEP's Executive Director, has remarked: 'I have known of no effective environmental action that was not preceded by public support, which is generated, in turn, by the free flow of accurate information.' The Authors of the 'Brundtland Report', Our Common Future, state 'We need to create more awareness and to mobilize people in all corners of the globe and in all walks of life.'

Nowadays there can be no doubt that the audio-visual medium - the one thousand million television sets and two thousand million plus transistor radios - is the way in which most people, most of the time, receive their information. It is the only medium that can reach all corners of the globe and people in all walks of life. And it is a medium that is subject to profound and lightning-quick change. Twenty years ago, at the time of the UN Conference on the Human Environment at Stockholm, television was a rich man's medium - but no longer. About half the sets are located outside the OECD countries, and their numbers are increasing all the time, together with the necessary delivery systems.

While newspaper circulation is declining, in the skies a 'star war' is happening. The transponders of satellites in geostationary orbit have created a new phenomenon: cross-frontier television. As with shortwave radio, governments can no longer control the information their citizens receive. Those that have tried to control it are giving up.

Numerous technologies and desseminating devices will deliver the messages that will mould public opinion in the 1990s. No doubt the Western-owned and -operated satellite news agencies such as CNN and ITN will continue to cover the seemingly inevitable environmental disasters. But television, let us never forget, is essentially an entertainment medium. Consequently it is going to be a hard struggle to keep responsible, scientifically rigorous, programming about environment and development on the air.

\footnotetext{
* On Communication and Education, and forming part of the first Geneva Environmental Meeting (GEM), to be described in the Conferences \& Meetings section of our next issue. - Ed.
} 
The governments of wealthy nations are beginning to respond to the audio-visual communications revolution. The United States and the major Western European countries are all now funding 'placement' services - sending out cassettes which present their countries in the best light. Some of these programmes are very good, but they are still — essentially — propaganda services.

\section{A New Threat from the Skies}

The key point - nowhere mentioned in the UNCED documents - is that, in the 1990s, the audio-visual medium will become, even more than it is today, a means to communicate alien messages about development. Advertisers are using it to encourage Western patterns of consumption. In India, for example, the advertising industry is developing a new generation of advertisements - of cigarettes, hair sprays, and so on - for consumers in the rural areas. This will do nothing to promote sustainable development, and nor will the 24 hours-a-day bombardment of viewers in the Caribbean with American advertisements that plug the materialistic way of life. One expert has described that bombardment of 'inane imagery' as a form of 'technopornography'.

As far as I am aware, virtually no attention has been given to the threat that this new era of global broadcasting will pose to any plan to address the wasting of the planet's cultural and ecological patrimony.

Ultimately, it will not be the governments of the world that will decide if Rio is a success but, rather, the 5.3 thousand million individual humans who live on this planet and are the actual points of interaction with the world environment. These are the actual shapers of our future. But what hope can there be for shaping a sustainable and equitable future if television imagery creates insatiable appetites for things that the embattled resource-base of our world cannot possibly supply? And what hope can there be for a better understanding of the interdependency of people around the world if most coverage is restricted to a few minutes of pictures of the latest disaster to overtake drought-stricken Africa, or of the poor huddled around polluting factories and nuclear reactors?

Setting up a mechanism to counter the depressing and the unsustainable is barely on the agenda at Rio. True, there are a number of very welcome recommendations for governments to support public environmental information services and to support ecological awareness campaigns. But nowhere is the crucial issue of editorial independence dealt with. Governments are - to put it mildly - very far from being the best guardians of information. That would be like putting the fox in charge of the chicken coop!

So, what is to be done? Is it all hopeless? Not necessarily. I come back to the One World project which, apart from the United States, has involved every major public-service broadcaster in the developed world as well as a range of UN and government agencies. From the outset, all participants accepted that all the output must be done on a strictly editorially-independent basis. The core output was Developing Stories - a series by outstanding film-makers from the developing world that were highly critical of the North and even of the elites in their own regions. Despite this, the Canadian and many European governments, through their development assistance agencies, chose to help finance the series.

This augurs well for keeping the coalition intact after Rio. But, reckoning on the increasing competition from a diversifying medium, much more needs to be done than simply ensuring that the One World coalition continues.

\section{Recommendations for Rio}

Having outlined the nature of the challenge, in the remainder of this comment I intend to deal with what I believe should be considered at Rio. I should add that these recommendations draw heavily on TVE's experience, which has already been tried and tested. So, as its Director, I at least know that they can work.

First, UNCED should recommend the establishment of an audio-visual exchange mechanism as an integral part of the information clearinghouse that UNEP and IUCN inter alia will be asked to set up. It is essential that such a system should be editorially independent.

On a modest scale, TVE has already set up such a mechanism. Since 1987, TVE has supplied over 9,000 titles to TV stations, NGOs, and educational institutions in the South and in Eastern Europe. As a matter of policy, close to half of these films were made by non-OECD-country producers. I am pleased to say that the demand is many times greater than we have the resources to meet.

One step that could be taken immediately after Rio would be for donors to agree on a common rights formula. This would ensure that, post-UNCED, a bank or library of copyright-free material will be built up. The common rights formula should allow for proceeds from sales to industrialized countries to be diverted to help to cover the costs of supplying the materials to non-OECD countries.

Second, and perhaps most important, the audio-visual arm of the clearinghouse should be a highly decentralized mechanism. 
A network composed of existing NGOs, video-distribution agencies, and so on, should be created. These, in effect, would be Video Resource Centres taking over in-country distribution and feeding the central mechanism with information about new programming that would be suitable for international transmission.

These two modest proposals are attainable now. The Agenda 21 document refers to the "establishment of an international Clearinghouse of information, technologies, and resources' within five years. An important point to make is that there is no need to wait so long. Within a year of Rio, building on what TVE has already achieved, a properly financed clearinghouse could be up-and-running.

But such a mechanism would be an essentially passive undertaking. It would not ensure, for example, that producers outside the Western countries were helped to step up coverage of environment and development.

Third, attention should therefore be given to setting up a fund to help train producers in the South and finance their productions. This could be a one-time-only collective grant, run on the interest from that investment and topped-up on a project-by-project basis.

The above three suggestions encompass, however, what would be essentially a 'programme placement' service. It would be heavily dependent on broadcasters' preparedness to continue transmitting this type of programming. But, as I have already outlined, the competition, already becoming severe from satellite, cable, and the video recorder, will become more so.

So, fourth the Clearinghouse should consider the acquisition of its own satellite transponder that would be powerful enough to compete and to provide an alternative to the existing news, sport, and entertainment, services,

The Canadian government's International Development Research Centre is already actively developing such a proposal. The obstacles are many, but surmountable. An 'Earth' satellite beaming 24 hours-a-day could be picked up directly by terrestrial broadcasters, captured by domestic users, and used by the cable operators for onward transmission. Let us not forget that CNN, now the byword for global broadcasting, started from very modest beginnings, and has already in some views been surpassed by ITN.

Fifth, and finally, UNCED should give priority attention to the proposal made in the second world conservation strategy, to set up a global watchdog organization.

Caring for the Earth (this second world conservation strategy) calls for the establishment of an organization along the lines of Amnesty International, essentially to monitor governments' compliance with international environmental legal instruments. Such an organization is desperately needed as a means to promote environmental democracy.*

There would obviously be an overlap with the proposed clearinghouse. No watchdog can be effective unless it has a means of publicizing its findings free from any possible government interference - and the best way to do that is through television.

\section{Conclusion}

In the limited space available I have tried to pinpoint what TVE sees as a major threat to putting the world on a path to sustainable development. Nothing is going to stop the process of homogenization already started by cross-frontier television. Even if it were desirable, it is not possible to suppress the free flow of imagery. The challenge facing Rio in this respect is to start a process which recognizes the need to respond adequately to the AV communications revolution.

The prospects of doing this successfully are not promising at present. That is why I have particularly appreciated this opportunity to record some thoughts on what needs to be done if we are to ensure that the coverage of complex environment and development issues continues to reach the world's television screens in the years after Rio.

ROBERT LAMB, Director

Television Trust for the Environment (TVE)

46 Charlotte Street

London WIP ILX

England, UK.

\footnotetext{
* Could not this somehow be linked with what now seems best called an 'International Court of Environment' and was recently proposed for Geneva - see page 176 of our preceding issue? - Ed.
} 